\title{
PREVALENCE OF DEPRESSION AT WOMEN DURING PREGNANCY- BY USING EDINBURGH POSTNATAL DEPRESSION SCALE (EPDS) INSTRUMENT
}

\author{
Mirela Çela ${ }^{1,3}$, Vuksan Kola ${ }^{2}$ \\ ${ }^{1 *}$ Faculty of Medicine, Neuroscience Department Psychiatric Service, Tirana, Albania; \\ ${ }^{2}$ UHC Mother Teresa, Neuroscience Department, Tirana, Albania; \\ ${ }^{3 *}$ National Center for Quality Safety and Accreditation of Health Institutions, Tirana, Albania; \\ *Corresponding Author Mirela Çela, e-mail: celamirela@gmail.com;
}

Received September 2019; Accepted October 2019; Published November 2019;

DOI: https://doi.org/10.31407/ijees9423

\begin{abstract}
Prevalence of depression during pregnancy ranges from $4 \%$ to $20 \%$. The World Health Organization identifies depressive disorders as the second leading cause of global disease burden by 2020. Groups of women at higher risk include (50-60\%) inner city women, mothers of pre-term infants and adolescents. This study aimed to determine the prevalence of antenatal depression and associated factors among pregnant women attending routine antenatal checkup in Primary Health Care Centers in Tirana Albania. The methodology we used is Edinburgh Postnatal Depression Scale (EPDS). This self-report instrument contains ten items ranked from 0 to 3 that reflect the patient's experience over the past week. The EPDS has been validated extensively for use in the postpartum period and during pregnancy. In this study were involved to be evaluated for PPD, patients from 4 primary health care centers in Tirana and from two departments of Obstetrical Gynecology University Hospital "Geraldine Queen" in Tirana and to find out the Prevalence of depression during pregnancy at the target group of this study. Patients that participated in the survey are anonymous in accordance to respect patient's right.
\end{abstract}

Keywords: postpartum depression, prevalence; 